\title{
Studies on the effect of Acrylic acid \& Methyl-meth-acrylate monomers on the Viscoelastic behavior of Divinylester resin of Bisphenol-A UV cured sheets
}

\author{
Meenu Teotia ${ }^{1}$ and R. K. Soni ${ }^{1}$ \\ ${ }^{I}$ Department of Chemistry, Chaudhary Charan Singh University, Meerut-250005, Uttar Pradesh, India \\ E-mail: teotiameenu@gmail.com
}

\begin{abstract}
Tg is important both as a measure of the degree of cure and for prediction of viscoelastic behavior of cured sheets DMA is an extremely versatile thermal analysis method that provides as much information about the physical properties of a sample in a single test. At the glass transition, the storage modulus decreases dramatically and the loss modulus reaches a maximum. In the present work, Vinyl ester resin based UV cured sheets were casted and analyzed for glass transition temperature with the help of DMTA. The thermal stability of the casted sheets was studied with derivative weight loss curves obtained through simultaneous TGA/DTA thermograms. The glass transition temperatures of the casted UV Cured sheets were found between $61-77^{\circ} \mathrm{C}$ corresponding to maximum tan delta values. On the basis of the findings presented in this article, it can be concluded that the glass transition temperature is decreasing on increasing the acrylic acid and methyl methacrylate concentration in UV curable formulations, which is indicating a decrease in degree of crosslinking but on the other hand mechanical properties have shown a remarkable increase. The specific gravity of the sheets was found in the range 1.46-1.21. However, after crosslinking with acrylate monomers, thermal stability of these UV cured sheets is increasing and hence the sheets could withstand relatively high temperatures without significantly affecting other properties. The average molecular weight between the cross links (Mc) of the cured formulations was also calculated from equilibrium shear modulus at thermodynamic temperature of $25^{\circ} \mathrm{C}$ and compared with theoretical values.
\end{abstract}

Keywords: Glass transition; UV Curing; DTA; DMA; TGA

\section{Introduction}

The viscoelastic property of polymer is studied by dynamic mechanical analysis where a sinusoidal force is applied to a material and the resulting displacement is measured. The storage modulus measures the stored energy, representing the elastic portion, and the loss modulus measures the energy dissipated as heat, representing the viscous portion. One important application of DMTA is measurement of the glass transition temperature of polymers. At the glass transition, the storage modulus decreases dramatically and the loss modulus reaches a maximum (1). The DMTA measurement provides the temperature dependent elastic component E' (storage modulus G') as well as non elastic component (loss modulus G"). The material loss factor or loss tangent, tan delta is the ratio of energy dissipated to energy stored per cycle of deformation. With DMTA measurement Tg values can be analyzed with high sensitivity (2). DMTA supplies an oscillating force, causing a sinusoidal stress to be applied to a sample, which generates a sinusoidal strain. By the measurement of the magnitude of the deformation at the peak of the sine wave and the lag between the stress and strain waves, properties such as the modulus, viscosity, and damping can be calculated (3). When this is performed through a range of temperatures, the changes in the flexural modulus of engineering resins as a function of temperature can be monitored, and this allows the identification of $\mathrm{Tg}$ and the melting point and the determination of the effects of these changes on load-bearing characteristics (4). Tg is important both as a measure of the degree of cure and for establishing a maximal temperature for use, that is, a material operational limit (5). When Tg of a polymer is exceeded, certain mechanical properties may be compromised severely. In addition, it is well understood that an increase in the moisture content will lower $\mathrm{Tg}$ of thermosetting polymers (6-7).

Chandra and Soni (8-13) have worked extensively on thermal and radiation curable systems and studied kinetics of bulk polymerization of divinyl ester by radical initiated thermal and photopolymerization. kinetics of thermally initiated radical polymerization of divinyl ester monomers and the effect of Bismaleimide Resin on Curing Kinetics of Epoxy-Amine Thermosets has also been studied using DSC. Further, the kinetics of photo-initiated radical polymerisation of modified epoxy resin and radical initiated photocopolymerisation of di(vinyl 2-hydroxy propanoate) ether of bisphenol-A and monomers was also investigated.

UV curing is an environmentally clean technology and offers a number of advantages over conventional methods of curing. Vinyl ester resins have been proved as good matrices in fiber reinforced composites, but their use as adhesives has been limited. Soni and teotia (14-15) have developed Vinyl ester resin 
based formulations that can be used as adhesives and also developed laminated glass composites which find diverse applications in automobile, railway and defence industries.

The dynamic, thermal and mechanical properties of the sheets are essentially required in order to find a suitable application for the developed sheets. Thermal gravimetric analysis is a type of testing that is performed on samples to determine changes in weight in relation to change in temperature (16-18). A derivative weight loss curve can be used to tell the point at which weight loss is most apparent. In the work presented here, glass transition temperatures, thermal properties and mechanical properties of the polymeric sheets casted by UV Curing method were determined to study the compositional effects and to check the suitability of Vinyl ester resin based sheets for different applications. The main objective was to calculate the differences in $\mathrm{Tg}$ values on addition of diluents in different ratios to obtain desirable properties for specified applications and to compare the degree of cure qualitatively of these UV cured sheets.

\section{Chemicals}

\section{Experimental}

Divinylester resin or epoxy diacrylate was used as functionalized oligomer which was synthesized through the reaction of DGEBA (diglycidal ether of Bisphenol A) with acrylic acid below $90^{\circ} \mathrm{C}$ for $4-5 \mathrm{~h}$ in the presence of triphenyl phosphine used as catalyst (reaction scheme 1). The DGEBA used was procured from singhal chemicals and was of LY556 grade. Acrylic acid (99\%, LR grade) was obtained from G.S. Chemicals PVT LTD and was stabilized with $0.02 \%$ hydroquinone monomethyl ether. Triphenyl phosphine was obtained from $\mathrm{CDH}$ chemicals and used as such without further purification. Methyl methacrylate (99\%, LR grade) stabilized with $0.01 \%$ quinol was procured from G. S. Chemical lab and Allied industries Bombay. Vinyl trimethoxysilane (98\%) was procured from sigma Aldrich. Woven fabric (glass fiber) was selected for this research as it exhibits good stability along with high impact resistance and toughness. Among many commercial photoinitiators we selected Irgacure 184 from CIBA because of its high initiation quantum yield and low coloration of photoproducts. Woven glass fiber was selected for preparing fiber reinforced film as they exhibit good stability along with high impact resistance and toughness.

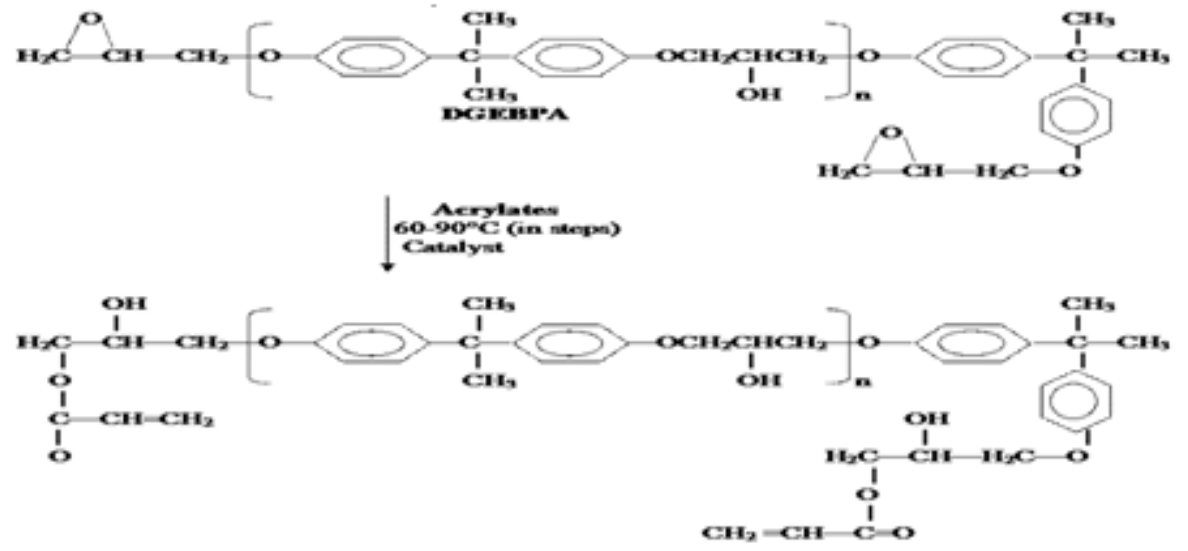

\section{Reaction Scheme 1: Synthesis of Divinyl ester Resin through reaction of DGEBPA (Diglycidyl ether of Bisphenol A) with acrylic acid.}

\section{Preparation of UV Curable Formulations}

Acrylic acid and methyl methacrylate were employed as reactive diluents. Small amounts of an organosilane (Vinyl trimethoxysilane) were added to most formulations to improve adhesion. The UV curable formulation contained $51 \%-80 \%$ oligomer, $20 \%-49 \%$ monomer, $0.1 \%$ silane and $3 \%$ photoinitiator (Irgacure 184) (table 1). All the ingredients were weighed and mixed thoroughly with the help of manual glass stirrers. The formulations were prepared one week in advance to their application to the substrate. These formulations are sensitive to light and hence these were kept in black colored containers and the beakers were also covered with black paper and used for casting of the sheets.

\section{Fabrication of UV cured Sheets}

The first step involved in casting of the sheet is the mold preparation. The outer shell of the mold, i.e. the base and the upper cover, were made of one inch thick acrylic sheets. PET sheets were used to cover the surface of the acrylic. The use of PET sheet prevents the resin from sticking on to its surface while curing, so the sheet can be easily removed from the mold. The dimensions of the mold were $150 \times 150 \mathrm{~mm}$, including the double sided adhering tape, $10 \mathrm{~mm}$ in width and $2 \mathrm{~mm}$ in thickness. The second step involves pouring the liquid formulation into the cavity and then allowing to stand in the designed frame so that air bubbles are removed if 
present. Now at this stage pressure is applied by clamping the mold with the help of screws present in the designed frame. After ensuring that no defect is present in the filled mold the whole assembly is put into UV chamber. Four Philips TL-D 18W BLB UV tubes (made in Holland) were arranged horizontally, two on each side in a UV chamber of dimensions $25 \times 15.5 \times 21$ inch. The time required to cure the sample completely was found in the range of 2-5 minutes depending upon the thickness of the sheet. The cured sheet is then removed from the mold. Glass fiber reinforced sheet was also prepared by sandwiching a piece of glass fiber in the prepared mold and then following the same process.

Table 1 Composition of the Formulations developed by using Divinylester resin (VER); Methylmethacrylate (MMA); Acrylic acid (AA); Irgacure, that has been used for preparing UV cured sheets:

\begin{tabular}{|c|c|c|c|c|c|c|}
\hline S.No. & Designation & VER $(\mathrm{g})$ & $\mathrm{AA}(\mathrm{g})$ & $\mathrm{MMA}(\mathrm{g})$ & $\begin{array}{c}\text { Irgacure } \\
(\mathrm{Wt} \%)\end{array}$ & $\begin{array}{c}\text { Organosilane } \\
(\mathrm{Wt} \%)\end{array}$ \\
\hline 1 & $\mathrm{AA}_{12}$ & 100 & 12 & 12 & 3 & .1 \\
\hline 2 & $\mathrm{AA}_{24}$ & 100 & 24 & 24 & 3 & .1 \\
\hline 3 & $\mathrm{AA}_{36}$ & 100 & 36 & 36 & 3 & .1 \\
\hline 4 & $\mathrm{AA}_{48}$ & 100 & 48 & 48 & 3 & .1 \\
\hline
\end{tabular}

\section{DMA \& TGA}

\section{Experimental procedure}

Specimens were machined to $2 \times 4 \times 15 \mathrm{~mm}$ dimensions from the casted sheets and placed in DMA instrument and oscillated at a frequency of $1 \mathrm{HZ}$. UV cured sheets have been characterized for glass transition temperature. Temperature sweep was performed at a temperature of $-20^{\circ} \mathrm{C}$ to $120^{\circ} \mathrm{C}$ using DMTA PERKIN ELMER Thermal Analyzer at a heating rate of $5^{\circ} \mathrm{C} /$ minute. The position of $\mathrm{Tg}$ was also predicted from the Fox equation;

$\frac{1}{T \text { gblend }}=\frac{W A}{T g A}+\frac{W B}{T g B}+\frac{W C}{T g C}$

Equation. $\ldots 1$

Where $\mathrm{W}_{\mathrm{A}}, \mathrm{W}_{\mathrm{B}} \& \mathrm{~W}_{\mathrm{C}}$ are the weight fractions of each polymer whose glass transition temperatures are $\mathrm{TgA}$, $\mathrm{TgB} \& \mathrm{TgC}$ respectively.

TGA of the casted sheets was carried out at a heating rate of $10{ }^{\circ} \mathrm{C} / \mathrm{min}$ from $50^{\circ} \mathrm{C}$ to $600^{\circ} \mathrm{C}$ with the help of thermal analyzer EXSTAR TG/DTA 6300 under nitrogen atmosphere (ASTM E1131, ISO 11358). From the TGA curves, the thermal stability of the UV cured sheets was studied. Further specific gravity of the sheets was also determined according to standard method ASTM D792, ISO 1183.

\section{Determination of Average molecular weight between cross links}

When a material is sufficiently cross-linked to form a solid with a reasonable degree of mechanical integrity above the glass rubber transition then DMA can be used to estimate its cross link density using the formula;

$$
\mathrm{G}=\rho R T / M C
$$

Equation. .2

Where $\mathrm{G}$ is the equilibrium shear modulus,

$\rho$ is the density

$\mathrm{R}$ is the gas constant,

$\mathrm{T}$ the thermodynamic temperature and

Mc the average molecular weight between cross links

Here, Mc can also be calculated by using the following equation:

$M c=X \times \frac{X w}{W}+Y \times \frac{Y w}{W}+Z \times \frac{Z w}{w}$

Equation .3

Where $\mathrm{W}=\mathrm{Xw}+\mathrm{Yw}+\mathrm{Zw}, \& \mathrm{Xw}, \mathrm{Yw} \& \mathrm{Zw}$ are weight fractions of Vinyl ester resin, Acrylic acid and Methyl methacrylate respectively and $X, Y \& Z$ are their molar masses.

\section{Determination of Mechanical Properties}

Hardness is the resistance of a material to deformation, particularly indentation or scratching. The test method is based on the penetration of a specified indenter forced into the material under specified conditions. The hardness of sheets was determined with the help of Durometer-D (ASTM D 2240 Shore-D). There are several scales of durometer, used for materials with different properties. The two most common scales, using 
slightly different measurement systems, are the ASTM D2240 type A and type D scales. The A scale is for softer plastics, while the $\mathrm{D}$ scale is for harder ones. Each scale results in a value between 0 and 100 , with higher values indicating a harder material.

The Tensile Properties of the casted sheets were determined as per the ASTM D 638 with the help of ZWICK UNIVERSAL TENSILE TESTING MACHINE (CAP.5 KN) (M1435). Tensile strength and elongation at break \% were determined keeping straightening speed of $1 \mathrm{~mm} / \mathrm{min}$ and straining rate of $5 \mathrm{~mm} / \mathrm{min}$ at room temperature of $25^{\circ} \mathrm{C}$. This test method covers the determination of the tensile properties of unreinforced and reinforced plastics in the form of standard dumbbell-shaped test specimens when tested under defined conditions of pretreatment, temperature, humidity, and testing machine speed. This test method and ISO 527-1 are technically equivalent. Different types of specimens are used for comparison between materials in different rigidity cases. Type IV specimen is used for Rigid/Nonrigid plastics.

The value of tensile strength and \% elongation at break was calculated by following equations:

\section{Tensile Strength $=$ Value of load $/$ Thickness $\times$ Width}

$\%$ Elongation at break $=($ Final length - Initial length $/$ Initial length $) \times 100$

Percentage elongation is considered to be a good indicator of a resins durability or toughness when subject to a mechanical load. Tensile Modulus of sheets was also determined. The tensile modulus is the ratio of stress to elastic strain in tension. A high tensile modulus means that the material is rigid, more stress is required to produce a given amount of strain.

\section{Determination of Tg by DMA}

\section{Results And Discussion}

For practical applications of UV cured formulations, it is important to know their viscoelastic properties, in particular their glass transition temperature and their elastic modulus. Even though DMTA is used extensively in Tg calculation, uncertainties still exist regarding the proper methods of accurate determination. The procedures described in several standards and recommendations can result in significantly different values of the same data, as discussed in detail by Wolfurm et al (2). This is due, in part, to the fact that $\mathrm{Tg}$ is a single temperature that represents a range over which the glass transition takes place (19-21). In an effort to simplify the determination of $\mathrm{Tg}$, it is commonly defined as the maximum of the damping ratio, E"/E' (tan delta), or the maximum of E".

Figures 1 and 2 show DMA thermograms of radical initiated photopolymerized $\mathrm{AA}_{12}$ sheet recorded over a temperature range $-20-120^{\circ} \mathrm{C} .75 .30^{\circ} \mathrm{C}$ is the temperature corresponding to maximum tan delta value for $\mathrm{AA}_{12}$ as obtained from its DMA thermogram. In figures 3 and 4 DMA thermograms of UV cured $\mathrm{AA}_{24}$ sheet are shown, in which the temperature corresponding to maximum tan delta value is lower $\left(66.40^{\circ} \mathrm{C}\right)$. The $\mathrm{Tg}$ value for $\mathrm{AA}_{24}$ was lowered by $8.90{ }^{\circ} \mathrm{C}$ which indicates that comparatively the extent of cross linking may be lesser in this sheet. Figures 5 and 6 are showing dynamic properties of $\mathrm{AA}_{36}$ sheet with respect to temperature alongwith static force, dynamic force and static displacement. The maximum tan delta value for the sheet was found at a temperature of $61.02{ }^{\circ} \mathrm{C}$ which is again lower as the monomer concentration in the formulation is $41.86 \%$. These values are in good agreement with specific gravity values of the casted sheets indicating decrease in cross linking density on increasing the amount of acrylic acid and methyl meth acrylate in the developed formulations.

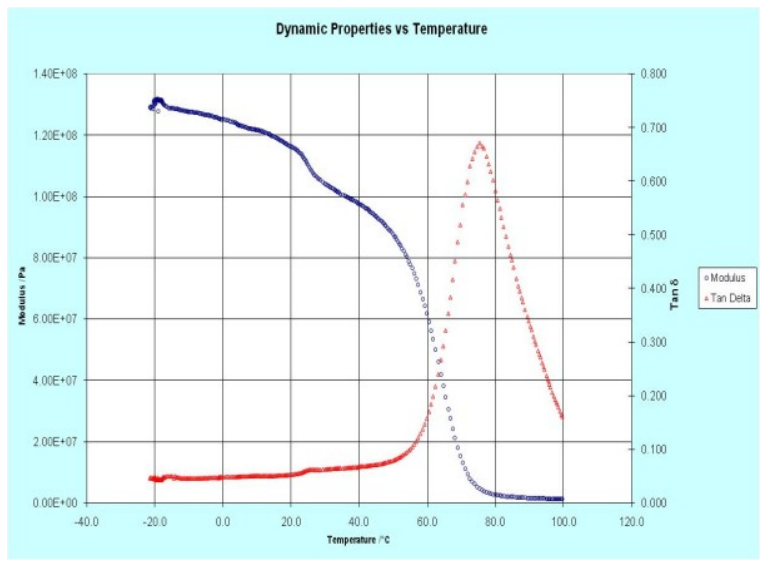

Figure 1 DMA Thermogram of $\mathrm{AA}_{12}$ sheet [Dynamic properties vs temperature] (Monomer concentration, 19.35\%)]

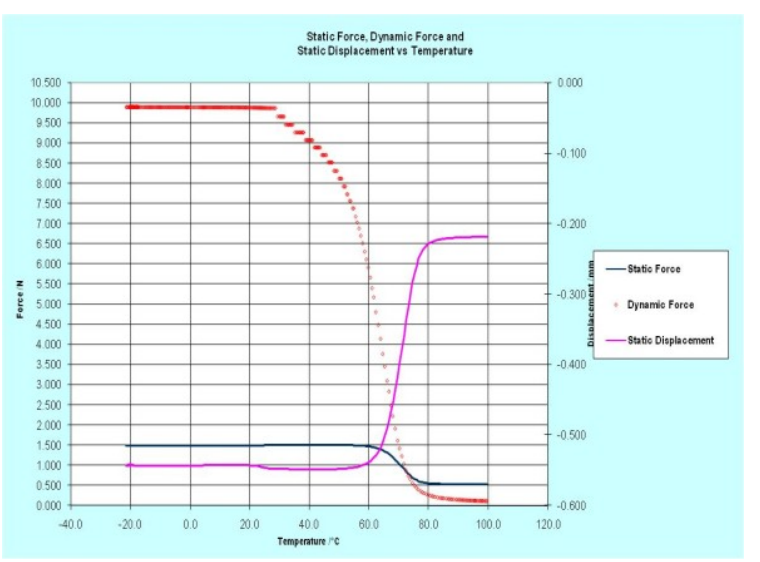

Figure 2 DMA Thermogram of $\mathrm{AA}_{12}$ sheet [Static force, Dynamic force and static displacement vs temperature] 


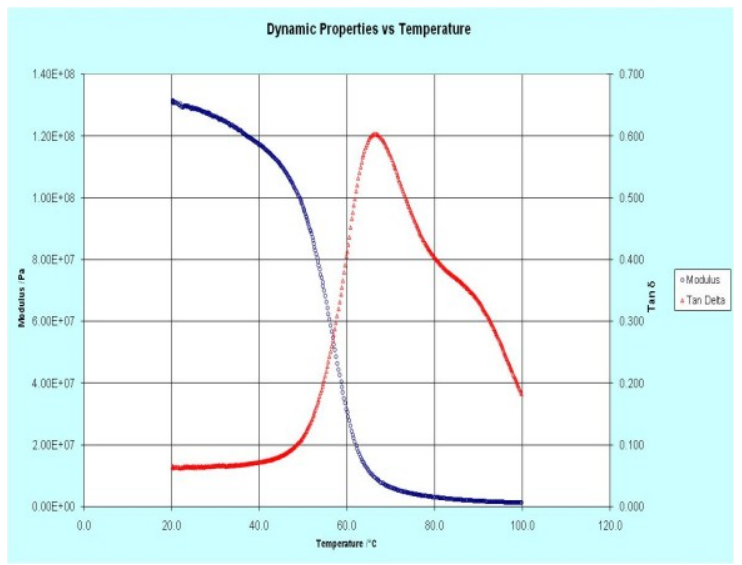

Figure 3 DMA Thermogram of $\mathrm{AA}_{24}$ film [Dynamic properties vs temperature] (Monomer concentration, $32.43 \%$ )]

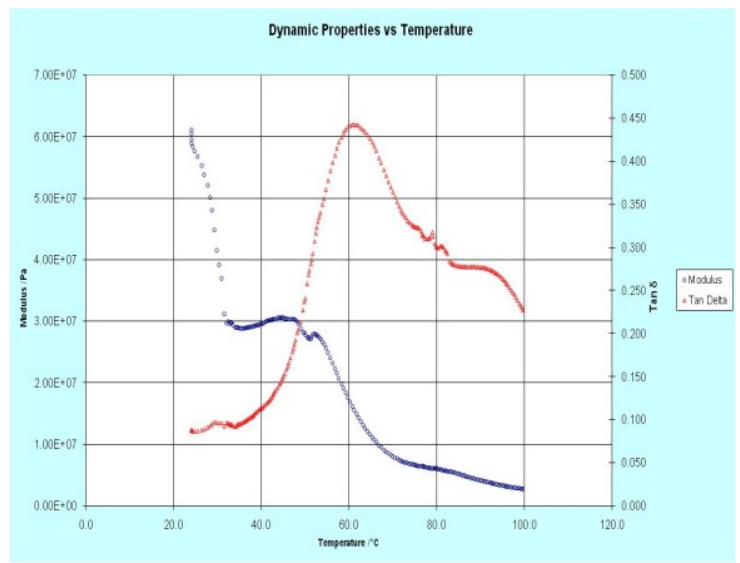

Figure 5 DMA Thermogram of $\mathrm{AA}_{36}$ film [Dynamic properties vs temperature] (Monomer concentration $41.86 \%$ )]

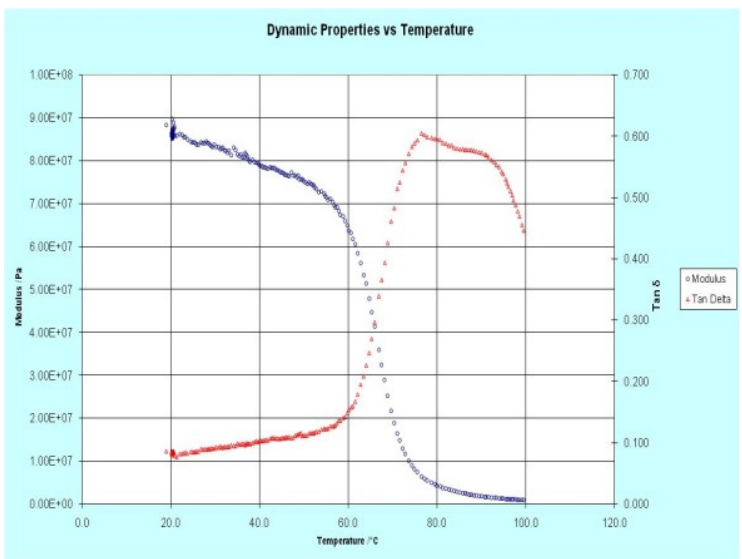

Figure 7 DMA Thermogram of $\mathrm{AAG}_{48}$ sheet with glass fiber [Dynamic properties vs Temperature] (Monomer concentration, 48.97\%)]

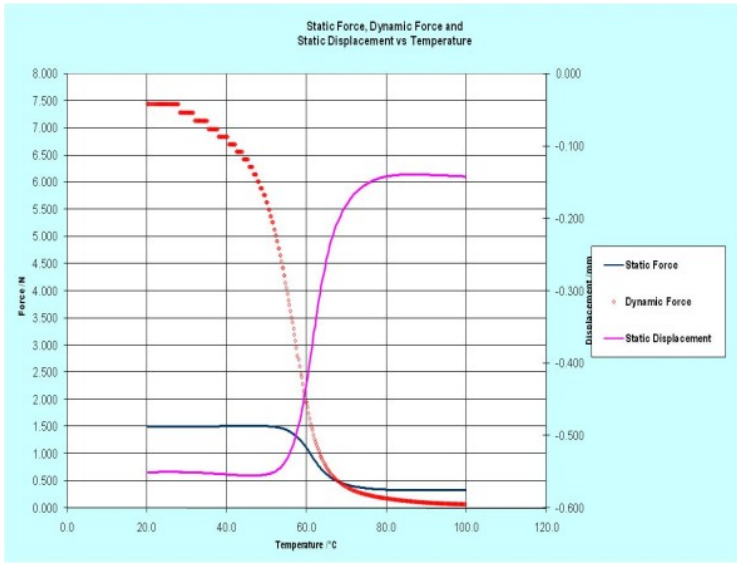

Figure 4 DMA Thermogram of $\mathrm{AA}_{24}$ sheet [Static force, Dynamic force and static displacement vs temperature]

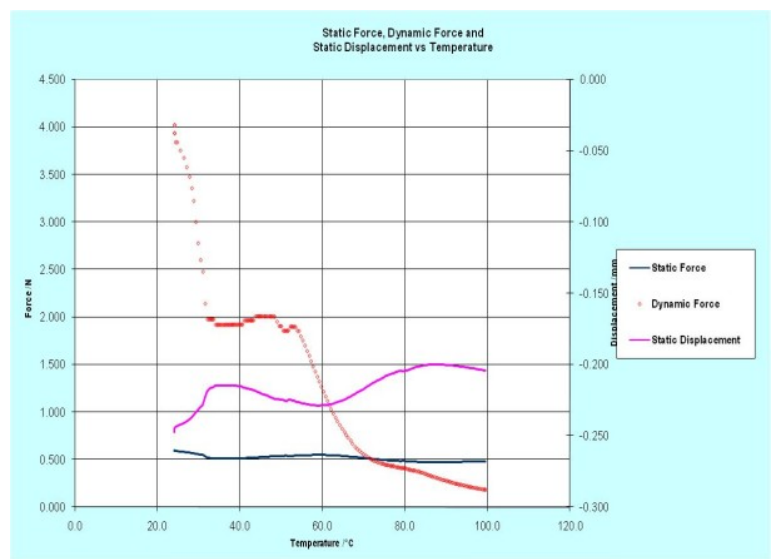

Figure 6 DMA Thermogram of $\mathrm{AA}_{36}$ sheet [Static force, Dynamic force and static displacement vs temperature]

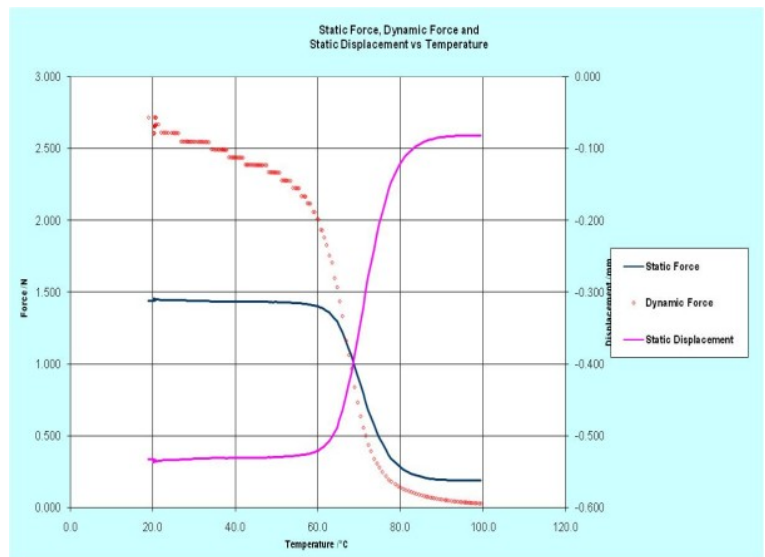

Figure 8 DMA Thermogram of $\mathrm{AAG}_{48}$ sheet [Static force, Dynamic force and static displacement vs temperature] 
In figures 7 and 8 DMA thermograms of $\mathrm{AAG}_{48}$ sheet are shown with different parameters. From the thermograms it was revealed that glass transition temperature of the sheet is around $76.50^{\circ} \mathrm{C}$ with maximum tan delta value 0.6050 which is more or less comparable with $\mathrm{AA}_{12}$ sheet with low monomer concentration. $\mathrm{Tg}$ of the fiber reinforced sheet was found to be higher regardless of the high monomer percentage (48.97\%). The higher glass transition temperature value may be attributed due to differences in the dynamic behavior i.e., stiffness, mass and damping properties of the sheets as the fibers are stiffer and can carry more load than matrix (22), the properties observed in samples loaded in three point bending may not be appreciably sensitive to variations in the mechanical properties of the matrix. One another reason may be because of greater amount of curing or crosslinking found in AAG48 sheet as evident from it's specific gravity value. Herzog et. al (23) have suggested that heat transfer through the fiber reinforced sheet/film may have been different than that in the resin during the DMTA temperature ramp because of the fiber reinforcement acting as a thermal energy conduit and also that the surface chemistry of the fibers reacted in such a way with the formulation to produce higher exotherm and therefore a higher degree of crosslinking than that found in the formulation alone. Further the Tg for neat resin is around $130^{\circ} \mathrm{C}$ corresponding to maximum tan delta value (23) which indicates that there is a remarkable decrease in the glass transition temperatures of UV cured sheets when these are cross linked with acrylate monomers.
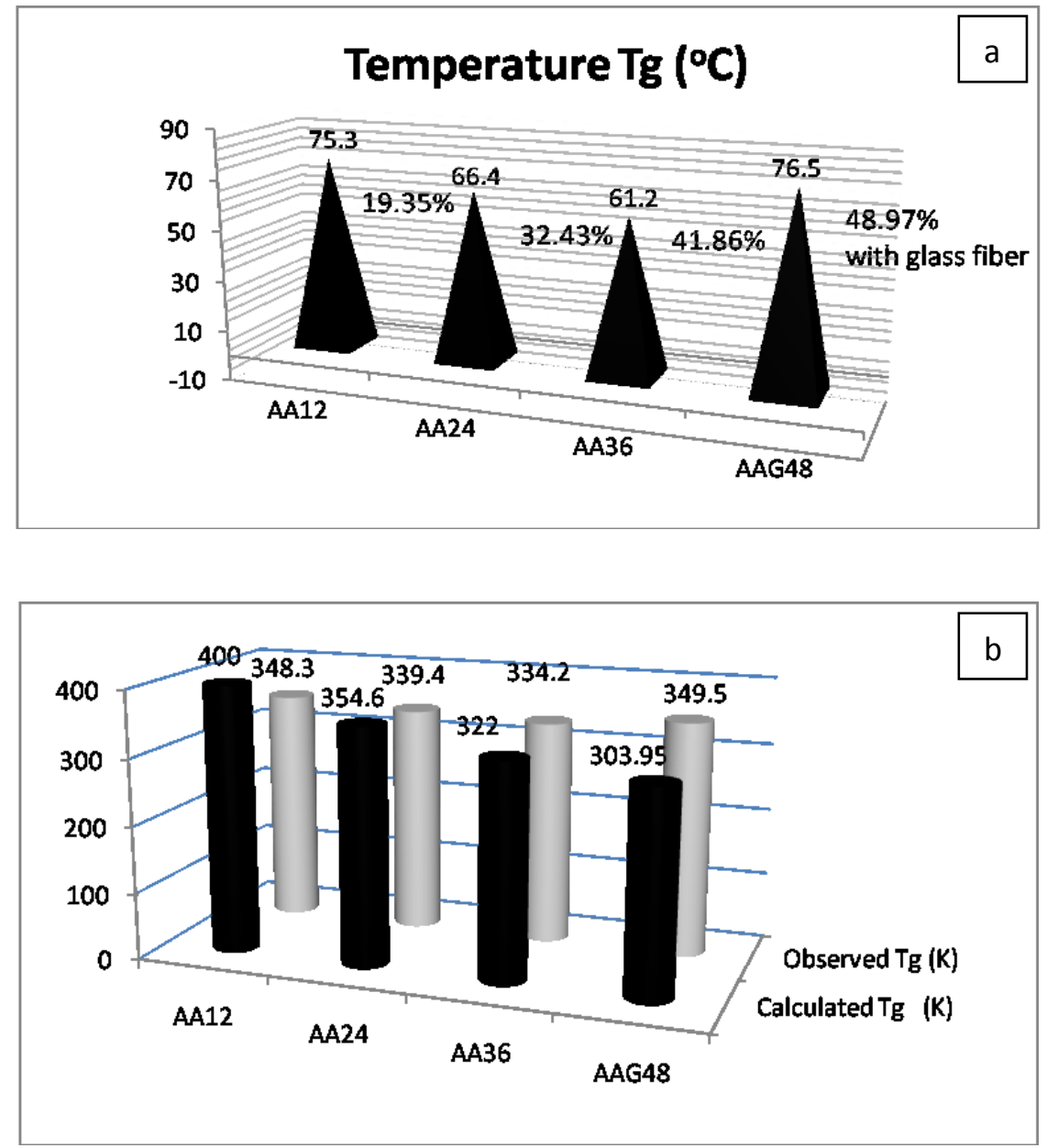

Figure 9: (a) Comparison of Tg values at different monomer concentrations (b) Comparative glass transition temperatures predicted from Fox Equation and experimental values obtained from DMA thermograms.

The glass transition temperatures of different formulations determined with the help of DMTA and their specific gravity have been listed in table 2. The glass transition temperature was also calculated using Fox Equation (table 3 ) and on comparison it was revealed that the formulation $\mathrm{AA}_{36}$ shows maximum proximity in comparison with other formulations. In figure 9(b), a comparison has been shown between calculated and observed $\mathrm{Tg}$ values for the cured sheets. For other formulations $\mathrm{AA}_{12}$ and $\mathrm{AA}_{24}$ the observed $\mathrm{Tg}$ was found lesser as $339 \& 348 \mathrm{~K}$. This shows that the cross link density decreases rapidly with addition of Acrylic acid and methyl meth acrylate to divinyl ester resin and all these formulations shows close proximity of $\mathrm{Tg}$ within range 
Studies on the effect of Acrylic acid \& Methyl-meth-acrylate monomers on the Viscoelastic behavior

of $15 \mathrm{~K}$. Thus it can be shown that the addition of acrylic acid and methyl meth acrylate decreases $\mathrm{Tg}$ of modified epoxy. This kind of result is well expected and has been shown by other researchers (24).

Table 2 Measured Glass Transition temperatures Tg for casted UV cured Sheets and Specific gravity of the sheets (D792)

\begin{tabular}{|l|l|l|l|l|}
\hline Film & $\begin{array}{l}\text { Monomer Concentration } \\
(\% \text { by weight })\end{array}$ & Tan delta & Temperature $\left({ }^{\circ} \mathrm{C}\right)$ & $\begin{array}{l}\text { Specific } \\
\text { Gravity }\end{array}$ \\
\hline $\mathrm{AA}_{12}$ & 19.35 & 0.6707 & 75.30 & 1.319 \\
\hline $\mathrm{AA}_{24}$ & 32.43 & 0.6028 & 66.40 & 1.252 \\
\hline $\mathrm{AA}_{36}$ & 41.86 & 0.4428 & 61.20 & 1.216 \\
\hline $\mathrm{AAG}_{48}$ & 48.97 & 0.6050 & 76.50 & 1.469 \\
\hline
\end{tabular}

Table 3 Shows Comparative glass transition temperatures predicted from Fox Equation and experimental values obtained from DMA thermograms.

\begin{tabular}{|c|l|l|l|l|l|}
\hline Formulation & $\mathrm{W}_{\mathrm{A}}(\mathrm{VER})$ & $\mathrm{W}_{\mathrm{B}}(\mathrm{AA})$ & $\mathrm{W}_{\mathrm{C}}(\mathrm{MMA})$ & Calculated Tg $(\mathrm{K})$ & Observed Tg $(\mathrm{K})$ \\
\hline $\mathrm{AA}_{12}$ & 0.806 & 0.096 & 0.096 & 400.00 & 348.30 \\
\hline $\mathrm{AA}_{24}$ & 0.806 & 0.162 & 0.162 & 354.60 & 339.40 \\
\hline $\mathrm{AA}_{36}$ & 0.806 & 0.209 & 0.209 & 322.00 & 334.20 \\
\hline $\mathrm{AAG}_{48}$ & 0.806 & 0.244 & 0.244 & 303.95 & 349.50 \\
\hline
\end{tabular}

Average molecular weight between cross links (Mc)

Mc of the UV cured sheets designated as $\mathrm{AA}_{12}, \mathrm{AA}_{24}$ and $\mathrm{AA}_{36}$ was calculated theoretically by using equation no. 3 in which the mole ratio of the divinyl ester resin of Bisphenol-A and monomers was taken 5:8. Further Mc was also estimated using equation no. 2 through equilibrium shear modulus $(\mathrm{G})$ obtained from DMTA curves and all these values are listed in table 4. As evident from the values, the observed average molecular weight between the cross links (Mc) for the UV cured sheets is less when compared with theoretically calculated values. It indicates that cross link density is less as expected, however we can correlate these findings with the observed mechanical properties. Observed $\mathrm{Mc}$ for $\mathrm{AA}_{36}$ sheet is $0.0527 \mathrm{Kg} / \mathrm{mol}$ which is higher than $\mathrm{AA}_{12}$ and $\mathrm{AA}_{24}$ sheets and this UV cured sheet also possess highest tensile strength among all the formulations, on the other hand this formulation also possess closest proximity of glass transition temperature as calculated using Fox equation. Hence it can be said that better mechanical properties are obtained when monomer concentrations are in the range between $30 \%$ and $40 \%$ (25).

Table 4 Shows Theoretical and Calculated Mc values for UV cured Sheets

\begin{tabular}{|c|l|l|l|l|}
\hline Formulation & $\begin{array}{l}\text { Theoretical Mc } \\
(\mathrm{Kg} / \mathrm{mol})\end{array}$ & Spectific gravity at 298 K & $\begin{array}{l}\text { Equilibrium shear Modulus } \\
(\mathrm{Pa})\end{array}$ & $\begin{array}{l}\text { Observed } \\
(\mathrm{Kg} / \mathrm{mol})\end{array}$ \\
\hline $\mathrm{AA}_{12}$ & 0.160 & 1.319 & $1.104 \times 10^{8}$ & 0.0297 \\
\hline $\mathrm{AA}_{24}$ & 0.167 & 1.252 & $1.288 \times 10^{8}$ & 0.0241 \\
\hline $\mathrm{AA}_{36}$ & 0.172 & 1.216 & $5.710 \times 10^{7}$ & 0.0527 \\
\hline
\end{tabular}

Table 5: Percentage weight loss of the sheets $\left(\mathrm{AA}_{12}-\mathbf{A A G}_{48}\right)$ under different temperature ranges obtained from TG curves

\begin{tabular}{|c|c|c|c|c|c|c|c|}
\hline \multirow{2}{*}{ Film } & \multirow{2}{*}{$\begin{array}{c}\text { Monomer } \\
\text { concentration ( } \% \text { by } \\
\text { weight })\end{array}$} & \multicolumn{6}{|c|}{ Cell Temperature $\left({ }^{0} \mathrm{C}\right)$} \\
\hline & & $50-100$ & $100-200$ & $200-300$ & $300-400$ & $400-500$ & $500-600$ \\
\hline $\mathrm{AA}_{12}$ & 19.35 & $0.92 \%$ & $2.98 \%$ & $5.05 \%$ & $11.10 \%$ & $55.05 \%$ & $23.50 \%$ \\
\hline $\mathrm{AA}_{24}$ & 32.43 & $0.97 \%$ & $3.14 \%$ & $5.76 \%$ & $11.63 \%$ & $57.30 \%$ & $21.16 \%$ \\
\hline $\mathrm{AA}_{36}$ & 41.86 & $1.30 \%$ & $4.27 \%$ & $7.77 \%$ & $15.06 \%$ & $52.45 \%$ & $18.85 \%$ \\
\hline $\mathrm{AAG}_{48}$ & 48.97 & $1.40 \%$ & $3.90 \%$ & $7.40 \%$ & $15.20 \%$ & $44.10 \%$ & $20.03 \%$ \\
\hline
\end{tabular}

Table 6: Percentage weight loss of the sheets $\left(\mathrm{AA}_{12}-\mathrm{AAG}_{48}\right)$ within two peaks observed in DTG curves

\begin{tabular}{|c|c|c|c|c|c|c|c|c|}
\hline \multirow[t]{2}{*}{ Film } & \multicolumn{4}{|c|}{$\begin{array}{c}\text { Peak I } \\
\end{array}$} & \multicolumn{4}{|c|}{ Peak II } \\
\hline & $\begin{array}{l}\text { Initial } \\
\text { Temp. }\end{array}$ & Final Temp. & $\begin{array}{l}\text { DTG } \\
\text { Maxima }\end{array}$ & $\begin{array}{l}\text { Weight loss } \\
(\%)\end{array}$ & $\begin{array}{l}\text { Initial } \\
\text { Temp. }\end{array}$ & Final Temp. & $\begin{array}{l}\text { DTG } \\
\text { Maxima }\end{array}$ & $\begin{array}{l}\text { Weight loss } \\
(\%)\end{array}$ \\
\hline $\mathrm{AA}_{12}$ & 410 & 450 & 424 & 39.04 & 560 & 590 & 578 & 12.58 \\
\hline $\mathrm{AA}_{24}$ & 400 & 450 & 425 & 48.67 & 550 & 580 & 569 & 12.41 \\
\hline $\mathrm{AA}_{36}$ & 410 & 450 & 422 & 37.67 & 550 & 600 & 567 & 12.54 \\
\hline $\mathrm{AAG}_{48}$ & 400 & 450 & 423 & 36.40 & 540 & 590 & 564 & 14.71 \\
\hline
\end{tabular}




\section{Thermal analysis of the sheets}

Figures 10-13 show simultaneous TG/DTG/DTA thermograms of sheets $\mathrm{AA}_{12}-\mathrm{AAG}_{48}$. All the data obtained from TG/DTG curves has been summarized in tables 5 and 6 . Up to $300{ }^{0} \mathrm{C}$ approximately $8-10 \%$ weight loss was observed in case of $\mathrm{AA}_{12}$ sheet and nearly 13-14\% weight loss was found for $\mathrm{AA}_{24}$ and $\mathrm{AA}_{36}$ sheets. On observing the percentage weight loss values upto $300{ }^{0} \mathrm{C}$ it was found that the decomposition behavior of sheets $\mathrm{AA}_{12}$ and $\mathrm{AA}_{24}$ is similar. However after $300{ }^{\circ} \mathrm{C}$ all the sheets are following approximately similar weight loss patterns. In the temperature range $50-100{ }^{0} \mathrm{C}, 0.92-1.4 \%$ weight loss was observed which is due to moisture and other volatile impurities present in the sheets. This weight loss is increasing gradually with monomer concentration in the crosslinked sheets. These results are consistent with water resistance properties of these sheets. Maximum weight loss i.e. 55-49\% was found in the temperature range $400-500{ }^{0} \mathrm{C}$ which corresponds to DTG peak I and $24-20 \%$ in the temperature range $500-600{ }^{\circ} \mathrm{C}$ corresponding to II DTG peak. The vinyl ester resins with styrene content gives DTG maxima around $300{ }^{\circ} \mathrm{C}$. From the observed TG/DTG thermograms of these sheets and the data obtained we can say that the sheets of the present work are thermally more stable than their base material. Glass fiber content in the $\mathrm{AAG}_{48}$ sheet was found to be approximately $7.5 \%$ on the basis of weight loss values at final decomposition temperature of II DTG peak in TG thermogram.
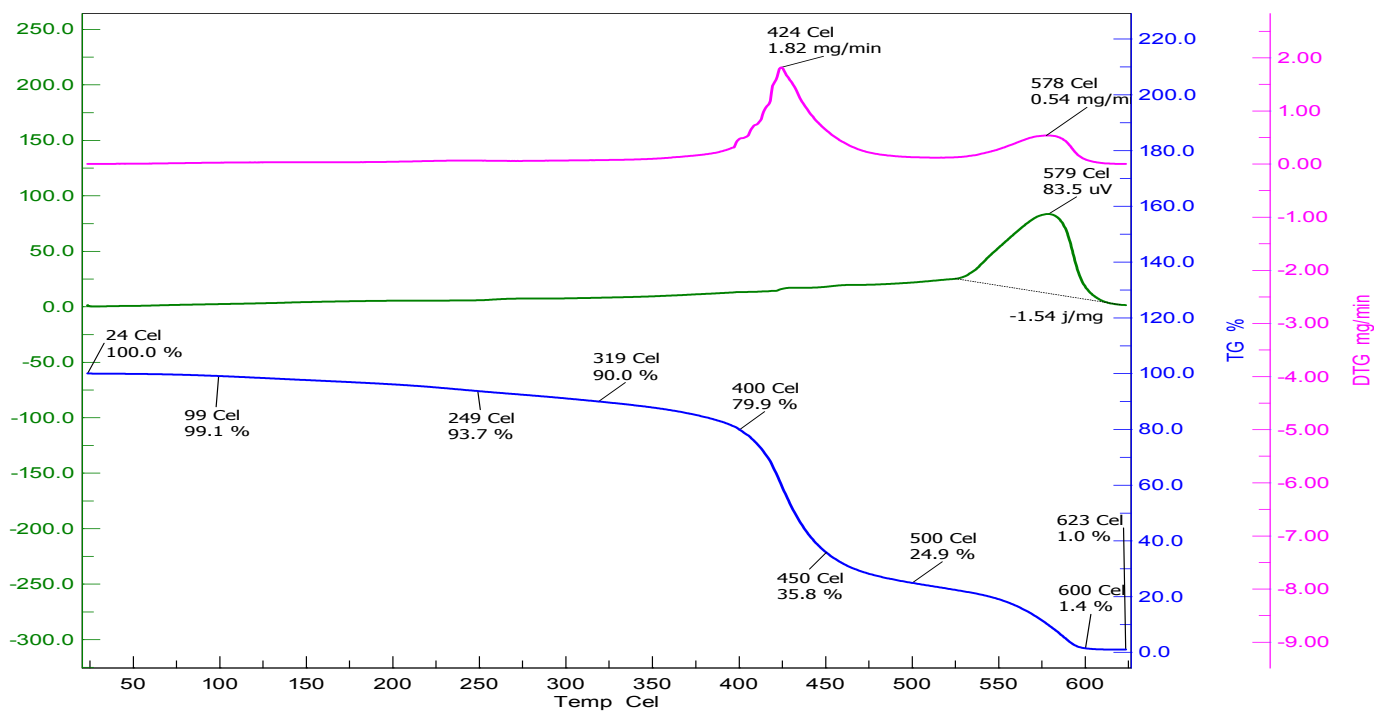

Figure 10: Simultaneous TG/DTG/DTA thermogram of $\mathrm{AA}_{12}$ sheet

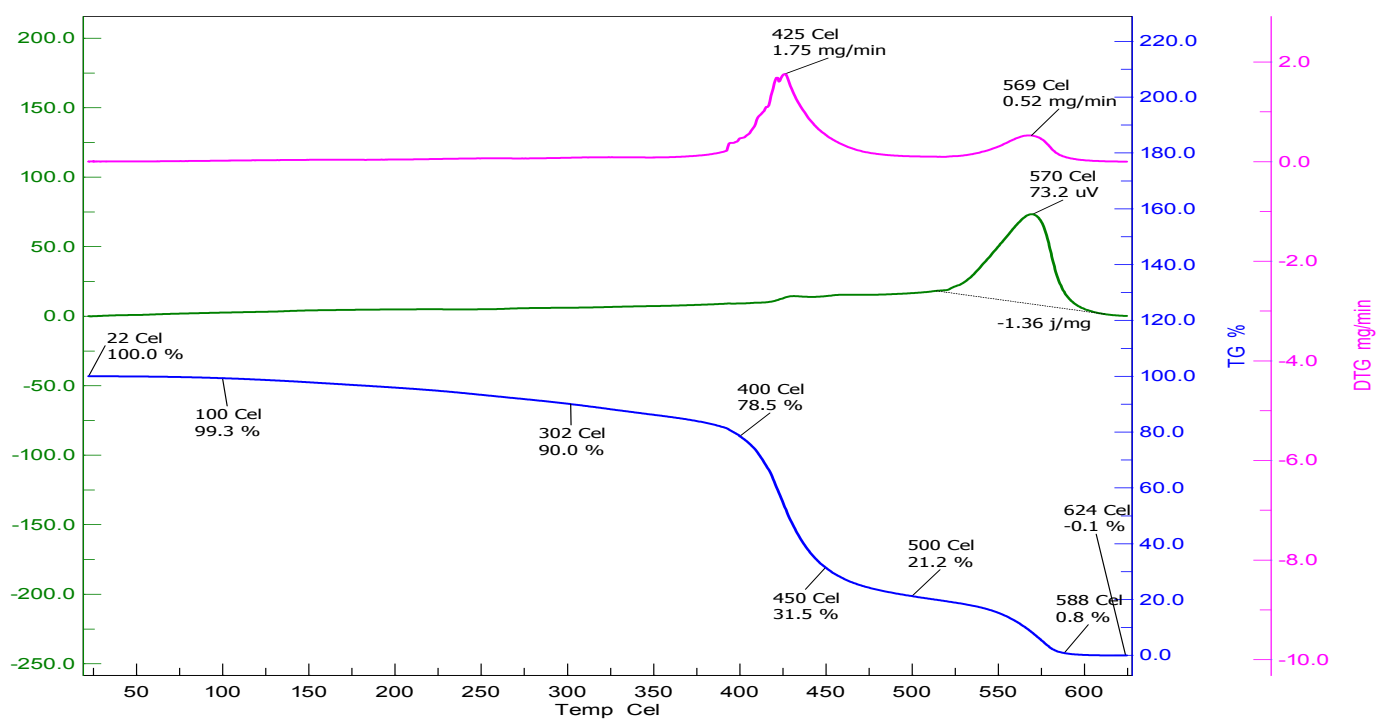

Figure 11: Simultaneous TG/DTG/DTA thermogram of $\mathbf{A A}_{24}$ sheet 


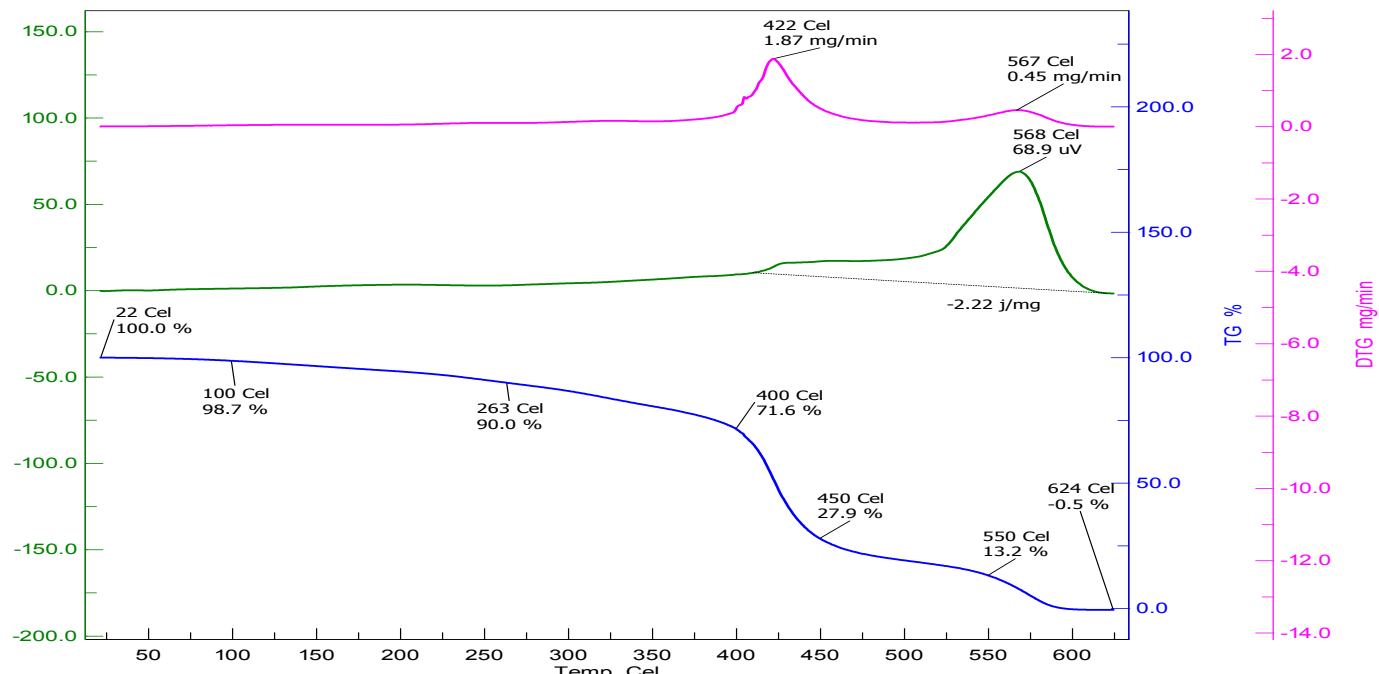

Figure 12: Simultaneous TG/DTG/DTA thermogram of $\mathbf{A A}_{36}$ sheet

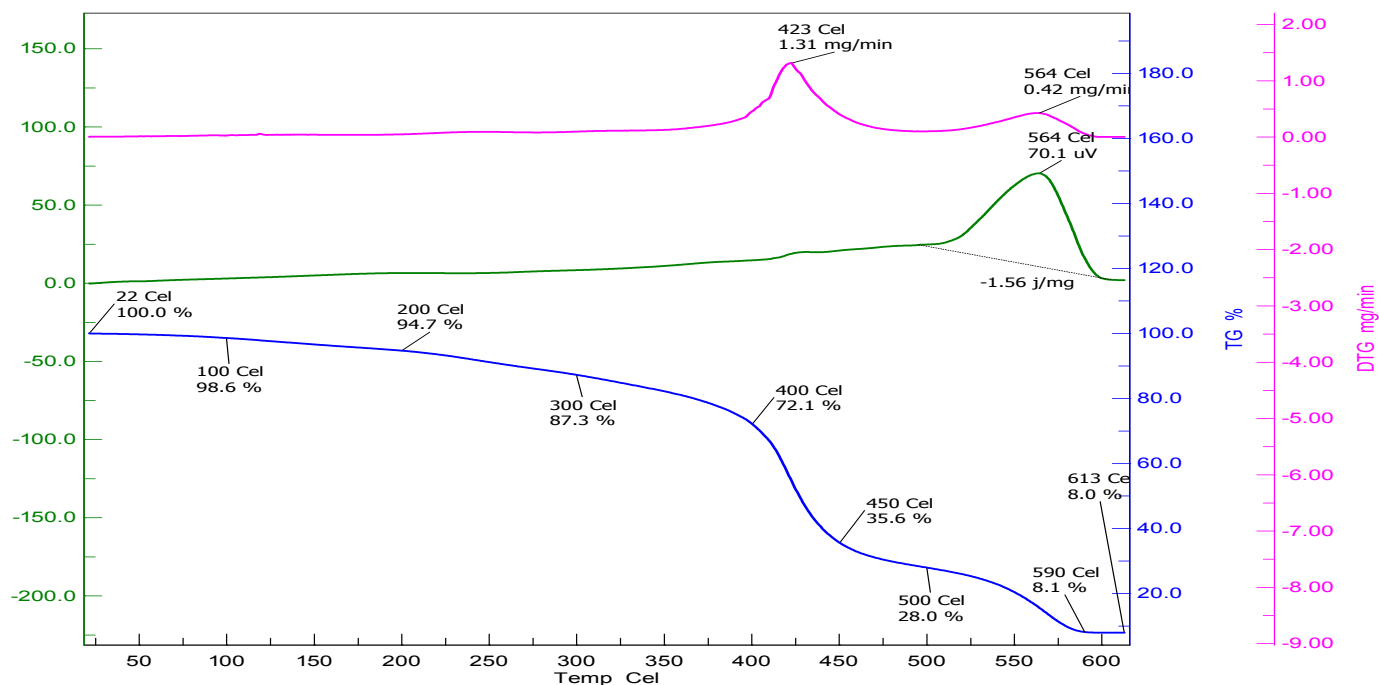

Figure 13: Simultaneous TG/DTG/DTA thermogram of $\mathbf{A A G}_{48}$ sheet

\section{Mechanical properties of the sheets}

Table 7 shows hardness (shore D), percentage elongation, tensile modulus and tensile strength values of casted sheets. The tensile strength of the sheets was found to increase from $\mathrm{AA}_{12}$ to $\mathrm{AA}_{36}$ and further it decreases to $355 \mathrm{~kg} / \mathrm{cm}^{2}$ for $\mathrm{AA}_{48}$ sheet (figure 14). Maximum tensile strength was obtained between $32.43 \%$ and $41.86 \%$ monomer concentration. Shi, W. and Ranby, B. (25) had investigated the effect of the concentration of a reactive acrylate monomer which serves as a reactive diluent on the laminate properties prepared by free radical polymerization (UV curing). They found that the tensile strength and tensile modulus were increasing with the monomer concentration and had a maximum between $30 \%$ and $40 \%$. Similar results were obtained in the present work. Fiber reinforced sheet $\mathrm{AAG}_{48}$ has shown a remarkable increase in tensile strength value of $849.98 \mathrm{~kg} / \mathrm{cm}^{2}$ as compared to $355.00 \mathrm{~kg} / \mathrm{cm}^{2}$ for $\mathrm{AA}_{48}$ (without fiber) sheet.

Table 7: Hardness (Shore D); Percentage Elongation; Tensile Modulus and Tensile strength of $2 \mathbf{~ m m}$ thick sheets prepared by UV curing

\begin{tabular}{|c|c|c|c|c|c|c|}
\hline S.No. & $\begin{array}{c}\text { Film } \\
\text { Designation }\end{array}$ & $\begin{array}{c}\text { Hardness } \\
\text { (Shore D) }\end{array}$ & $\begin{array}{c}\text { Percentage } \\
\text { elongation }\end{array}$ & $\begin{array}{c}\text { Tensile modulus at } \\
2.5 \% \text { elongation } \\
\left(\mathrm{Kg} / \mathrm{cm}^{2}\right)\end{array}$ & $\begin{array}{c}\text { Tensile strength } \\
\left(\mathrm{Kg} / \mathrm{cm}^{2}\right)\end{array}$ & $\begin{array}{c}\text { Strain at } \\
\text { failure }\end{array}$ \\
\hline 1 & $\mathrm{AA}_{12}$ & 85 & 4.65 & 11175.20 & 551.01 & 1.86 \\
\hline 2 & $\mathrm{AA}_{24}$ & 84 & 4.77 & 10621.60 & 559.47 & 1.90 \\
\hline 3 & $\mathrm{AA}_{36}$ & 83 & 5.15 & 11213.60 & 590.30 & 2.06 \\
\hline 4 & $\mathrm{AA}_{48}$ & 82 & 4.65 & 8049.20 & 355.00 & 1.86 \\
\hline 5 & $\mathrm{AAG}_{48}$ & 87 & 3.32 & 539.63 & 849.98 & 1.32 \\
\hline
\end{tabular}




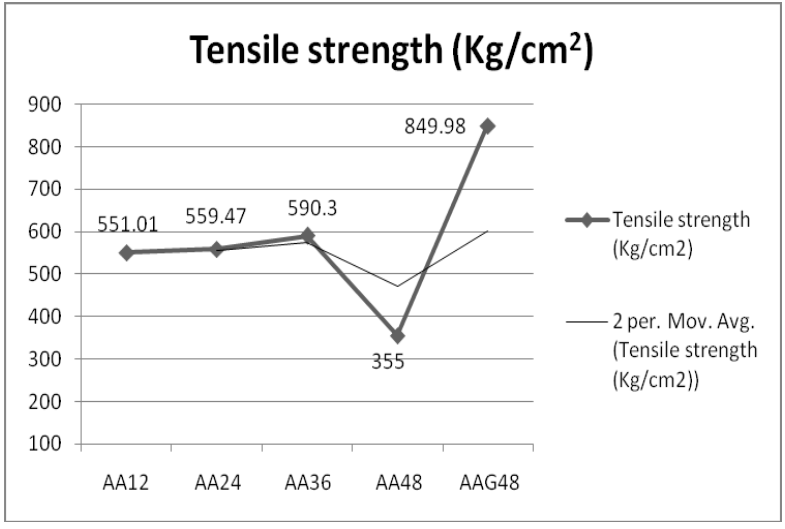

Figure 14: Tensile strength vs. Monomer Concentration in UV cured sheets

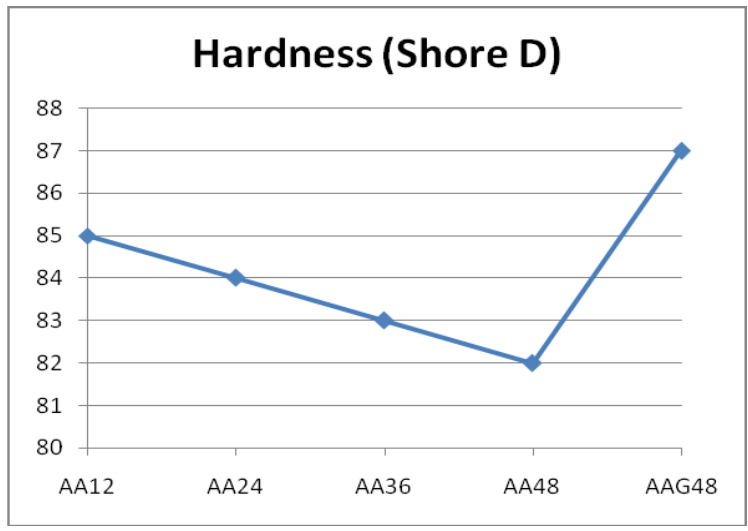

Figure 15: Film Hardness vs. Monomer Concentration in UV cured sheets

A regular increase was observed in percentage elongation values of $\mathrm{UV}$ cured sheets from $\mathrm{AA}_{12}$ to $\mathrm{AA}_{36}$ which is indicating an increase in flexibility of the sheets which is also been supported by $\mathrm{Tg}$ values of the sheets. Further, there is a decrease in tensile modulus from sheet $\mathrm{AA}_{12}$ to $\mathrm{AA}_{24}$ and a sudden increase for $\mathrm{AA}_{36}$ sheet and then it decreases in case of $\mathrm{AA}_{48}$ sheet. Sheet $\mathrm{AA}_{36}$ possess highest tensile modulus and highest tensile strength, so we can say that sheet $\mathrm{AA}_{36}$ is strong as well as tough among all these casted films. Plastics do not stretch or deform so easily, to know how well a material resist deformation, tensile modulus is measured. Shore D Hardness of the UV cured sheets was found in the range 87-82. There is a gradual decrease in hardness values as the concentration of monomers is increasing from sheet $\mathrm{AA}_{12}$ to $\mathrm{AA}_{48}$ (figure 15).

\section{Conclusions}

In this work, the effect of acrylic acid and methyl methacrylate on Viscoelastic and mechanical properties of UV cured sheets have been studied with reference to monomer ratio and degree of cross linking. The great advantage of these purely acrylate formulations is that these are one pack formulations with a long pot life time. The glass transition temperature of modified epoxy was decreased on addition of acrylic acid and methyl meth acrylate in the UV curable formulations. The observed glass transition temperatures were found in good agreement with calculated values through Fox equation and also with specific gravity data of the sheets. Observed cross linking density values indicates lesser amount of cross linking than expected, due to presence of unreacted monomers in the cured sheets which can be further studied using post curing methods. There is a remarkable increase in mechanical properties of the UV cured sheets when the monomer concentration is between $30 \%$ and $40 \%$. Sheet $\mathrm{AA}_{36}$ has shown highest degree of cross linking and improved mechanical properties. Further, from the observed TG/DTG thermograms of these films and the data obtained it was concluded that the sheets of the present work are thermally more stable than their base material. After crosslinking with acrylate monomers, thermal stability is increasing and hence these sheets could withstand relatively high temperatures without significantly affecting other properties. Fiber reinforced film was showing excellent mechanical properties with a $\mathrm{Tg}$ value of $76.50^{\circ} \mathrm{C}$ and hence can be used where high impact strength is required.

Acknowledgement: The financial support by Council of Scientific and Industrial Research is gratefully acknowledged.

\section{References:}

[1]. Luckenbach, TA Rheometrics, (accessed April 2004) Inc. http://www.sealseastern .com/PDF/DynamicMechThermalAnal.pdf.

[2]. Wolfrum J, Ehrenstein, GW, Avondet M A (2000) J Compos Mater 34:1788-1807.

[3]. Menard KP (1999) Dynamic Mechanical Analysis: A Practical Introduction; CRC: Boca Raton, FL.

[4]. Sepe M P (1992) Adv Mater Process 141:32.

[5]. Prime RB (1981) In Thermal Characterization of Polymeric Materials; Turi, EA, Ed.; Academic: Brooklyn, p-1380.

[6]. Boey FYC, Lee T H, Sullivan PL (1994) J Mater Sci 29:5985.

[7]. Jones H N, Keller TM (2002) NRL Review, U.S. Naval Research Lab: Washington, DC.

[8]. Chandra R, Soni RK (1993) Polymer International 31 (3):239-245.

[9]. Chandra R, Soni RK (1994) Progress in Polymer Science 19 (1):137-169.

[10]. Chandra R, Soni RK (1995) Polymer International 38 (2):147-152. 
[11]. Chandra R, Rajabi L, Soni RK (1996) Journal of Applied Polymer Science 62:661 - 671.

[12]. Chandra R, Thapliyal BP, Sehgal B, Soni RK (2007) Polymer International 29(3): 185-190.

[13]. Chandra R, Soni RK, Murthy SS (2007) Polymer International DOI: 10.1002/pi.4990310314

[14]. Soni RK, Teotia M, Dutt K (2010) J. of Applied polymer science 118(2):638-645.

[15]. Soni RK, Teotia M (2011) International Journal of Current Chemistry 2(2):117-127.

[16]. Overney RM, Buenviaje C, Luginbuhl R, Dinelli F (2000) J Themal Analysis and Calorimetry 59:205-225

[17]. Galusek D, Lences F, Sajgalík P, Riedel R(2008) J Mining and Metallurgy 44:35 - 38.

[18]. Kumar M, Verma V, Kumar V, Nayak SK, Yadav SB, Verma P (2010) J Chem. Pharm. Res. 2(5):181-192.

[19]. Work Item WK278; (2003) American Society of Testing Materials: West Conshohocken, PA,

[20]. Sperling LH (2001) Introduction to Physical Polymer Science; Wiley: New York,.

[21]. Bryant, E (1998) The Rapid Prototype Development Laboratory, University of Dayton Research Institute.

[22]. Akay M (1993) Compos Sci Technol 47:419.

[23]. Benzamin H, Douglas JG, Roberto LA, Barry G (2005) Journal of applied polymer science 97:2221-2229.

[24]. Robert AS, Nicholas AP (1999) Macromolecules 32:6139-6148.

[25]. Shi W, Ranby, B (1994) J. Appl. Polym. Sci., 51:1129. 